\title{
Evaluation of the Technical Condition of the Active Part of the High Power Transformer Based on Measurements and Analysis of Vibroacoustic Signals
}

\author{
Sebastian BORUCKI, Andrzej CICHOŃ, Henryk MAJCHRZAK, Dariusz ZMARZŁY \\ Institute of Electrical Power and Renewable Energy \\ Opole University of Technology \\ Prószkowska 76, 45-758 Opole, Poland; e-mail: s.borucki@po.opole.pl \\ (received June 20, 2016; accepted November 10, 2016)
}

\begin{abstract}
This article presents the results of research connected with the development and industrial use of vibroacoustic methods for the evaluation of the technical condition of the active part of transformers. The article presents the results of the analysis of vibrations generated by the high power transformer in which a defect was found on the basis of tests of oil carried out using the chromatography tests. In order to confirm the damage of the active part of this transformer, vibroacoustic measurements were performed in three states of its operation. The measurement using the classical vibroacoustic method included the registration of vibrations at the idle speed and during the load operation of the transformer. The original diagnostic method, so-called the modified vibroacoustic method, was also used during the measurement. The analysis of signals recorded using the classical vibroacoustic method was carried out in the frequency domain by indicating the amplitude of even harmonic vibrations. However, the analysis of signals measured during the commissioning of the transformer was conducted in the time-frequency domain using the short-time Fourier transform (STFT), continuous wavelet transform (CWT), and discrete wavelet transform (DWT). On the basis of the analysis of the results obtained it was stated that the increased level of vibrations of this transformer is a consequence of the loss of rigidity of the mechanical structure of its core.
\end{abstract}

Keywords: vibration; vibroacoustic method; core; power transformer; transformer diagnostics.

\section{Introduction}

Vibroacoustic methods for the evaluation of the technical condition of various devices are more and more commonly used in various fields. It is due to the fact that the vibroacoustic diagnostics does not require permanent or temporary damage to the structure of the device. Vibroacoustic methods are used in the diagnostics of rotating machines, such as turbines, compressors, ventilators, pumps, engines, and in relation to static machines (DwOJAK et al., 1999; SzYMANIEC, 2006; WotzKa et al., 2013). As a result of the analysis of vibrations generated during the operation of each of the above-mentioned devices, the technical condition of inaccessible units of the tested device may be evaluated. The application of vibroacoustic methods in the diagnostics of high power transformers mostly allows for the evaluation of the technical condition of the core of the transformer. The discussed methods are more and more commonly used in relation to transformers, in particular in relation to step- up transformers and high power mains transformers. In conjunction with other diagnostic methods they can provide information on the technical condition of the structure of mechanical parts and the condition of the main insulation of the transformer (BARTOLETTTI et al., 2004; Mizokami et al., 1997; Shengchang et al., 2006; LEONARD et al., 2000).

The aim of vibroacoustic measurements is to determine the level of mechanical vibrations of the tested transformer and, in particular, its core and, thus, to check the technical condition of the entire unit. The criteria for the evaluation of measured vibrations are determined to achieve the following goals:

1) to ensure reliable operation of the tested transformer,

2) to forecast the up-time of the transformer by detecting core damage and determining the dynamics of its development,

3) to minimise the influence of vibrations generated by the core on the winding and the entire structure of the tested transformer. 
The article presents the results of measurements and analysis of mechanical vibrations of the high power transformer in case of which an internal defect was suspected on the basis of chromatography tests of oil. In order to confirm the damage to the active part of this transformer, vibroacoustic measurements were carried out in three states of its operation. Measurements using the classical vibroacoustic method included the registration of vibroacoustic signals at the idle speed and during the load operation of the transformer. The original diagnostic method patented at the Opole University of Technology, so-called modified vibroacoustic method, consisting in the measurement and analysis of vibrations of the transformer at the time of starting was also used during the measurements of mechanical vibrations (BORUCKI, 2012b).

\section{Characteristics of the tested object and use of measurement instruments}

The mains transformer installed in one of the stations of the national transmission and distribution system was subject to vibroacoustic tests in three states of its operation: at idle speed, during the load operation, and at the time of commissioning. Table 1 presents the basic rated parameters of the diagnosed unit and Fig. 1 presents the general view of the transformer at the work station.

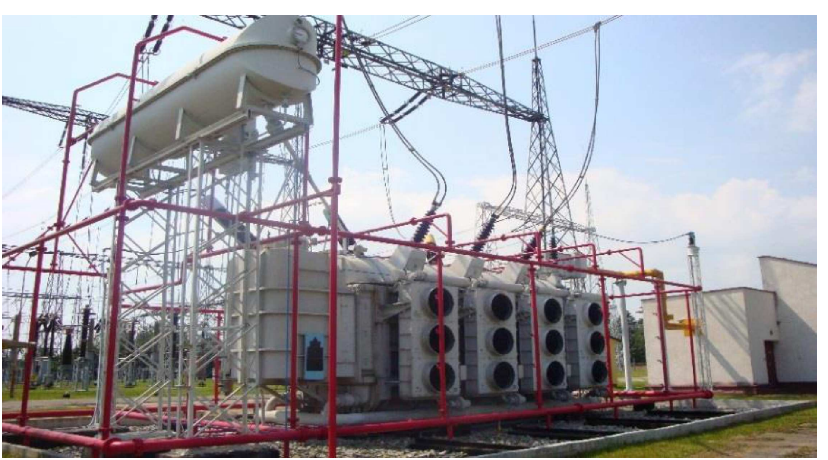

Fig. 1. General view of the tested transformer at the work station.

The results of chromatography tests (DGA) were the factor determining the performance of vibroacoustic measurements of the transformer TFR 250000/400. The quantitative evaluation of concentration of gases typical of the tested unit showed the high concentration of so-called flammable gases (Table 2), in par-

Table 1. Basic rated parameters of the tested transformer.

\begin{tabular}{|ll|ll|}
\hline Manufacturer: & ELTA & Type: & TFR 250000/400 \\
\hline Serial number: & 169785 & Manufacture year: & 1980 \\
\hline Power: & $250 / 250 / 50$ MVA & Design: & outdoor \\
\hline Cooling: & OF-AF & Number of phases: & 3 \\
\hline Frequency: & $50 \mathrm{~Hz}$ & Group: & Yy0d11 \\
\hline Rated voltage: & & Rated current: & \\
\hline Upper voltage: & $400 \mathrm{kV}$ & Upper voltage: & $361 \mathrm{~A}$ \\
\hline Lower voltage: & $123 \mathrm{kV}$ & Lower voltage: & $1173 \mathrm{~A}$ \\
\hline Medium voltage: & $31.5 \mathrm{kV}$ & Medium voltage: & $961 \mathrm{~A}$ \\
\hline
\end{tabular}

Table 2. Results of chromatography tests of oil of the tested transformer.

\begin{tabular}{|c|l|c|c|}
\hline \multirow{2}{*}{ No. } & \multirow{2}{*}{ Identified gas components } & \multicolumn{2}{|c|}{ Gas concentration in the oil sample taken [ppm] } \\
\cline { 3 - 4 } & & Tested transformer & Typical concentrations \\
\hline 1. & Hydrogen $-\mathrm{H}_{2}$ & $\mathbf{5 6 2 4}$ & 350 \\
\hline 2. & Methane $-\mathrm{CH}_{4}$ & $\mathbf{2 7 4}$ & 200 \\
\hline 3. & Ethane $-\mathrm{C}_{2} \mathrm{H}_{6}$ & 83 & 170 \\
\hline 4. & Ethylene $-\mathrm{C}_{2} \mathrm{H}_{4}$ & 115 & 260 \\
\hline 5. & Acetylene $-\mathrm{C}_{2} \mathrm{H}_{2}$ & None & 70 \\
\hline 6. & Propane $-\mathrm{C}_{3} \mathrm{H}_{8}$ & 25 & 30 \\
\hline 7. & Propylene $-\mathrm{C}_{3} \mathrm{H}_{6}$ & 28 & 40 \\
\hline 8. & Butane $-n-\mathrm{C}_{4} \mathrm{H}_{10}$ & - \\
\hline 9. & Carbon monoxide $-\mathrm{CO}$ & 2 & 260 \\
\hline 10. & Carbon dioxide $-\mathrm{CO}$ & 214 & 4000 \\
\hline 11. & Air & $\mathbf{6 7 9 4}$ & - \\
\hline 12. & Total amount of flammable gases & 37641 & $<2500$ \\
\hline
\end{tabular}


ticular hydrogen, as well as the increased amount of methane and the clear presence of ethane, ethylene, propane and propylene. Additionally, the presence of relatively large amounts of carbon dioxide proved that the overheating of the insulation system of the active part of this device was developing. On the basis of the DGA it was stated that the occurrence of local overheating of the core caused by its loosening may be the likely cause of "gassing" of the transformer.

Mechanical vibrations of the diagnosed transformer were measured using the system Pulse DYN-XI by the Brüel \& Kjær company, the general view of which is presented in Fig. 2. The measuring box used was characterized by four separate channels, 24-bit resolution, the possibility of parallel measurements without multiplexing, and additionally it was equipped with battery power supply which made it possible to separate the entire system from interfering signals present in the substation.

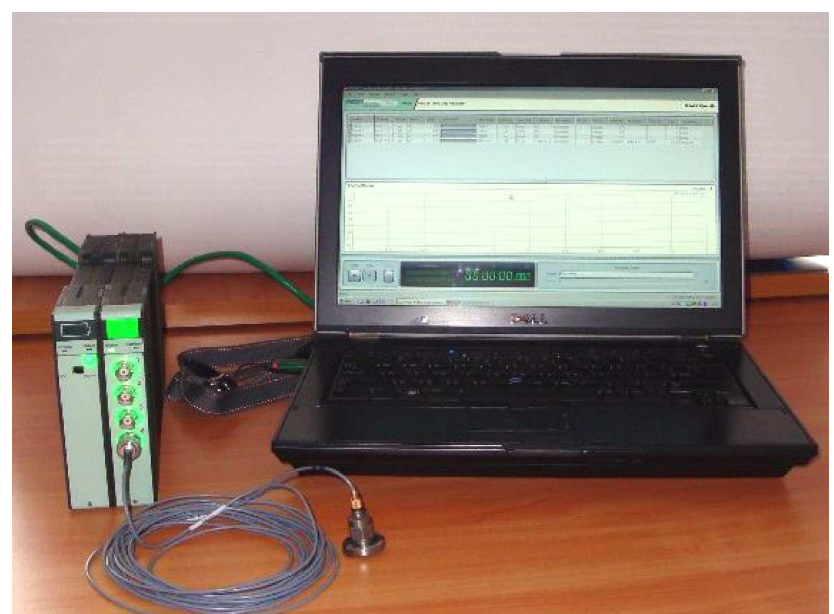

Fig. 2. General view of the measurement instruments used.

During the measurements, four single-axis accelerometers of type 4514-B-001, manufactured by the Brüel \& Kjær company, characterised by the sensitivity $10 \mathrm{mV} / \mathrm{ms}^{2}(f=160 \mathrm{~Hz})$, resonant frequency $f_{\text {rez }}=32 \mathrm{kHz}$ and linear bandwidth in the range from $5-10000 \mathrm{~Hz}$ were used. A calibrator of type 4294 by the Brüel \& Kjær company with standard frequency $f=159.15 \mathrm{~Hz}$ and acceleration $g=10 \mathrm{~m} / \mathrm{s}^{2}$ was used as the vibration standard during the calibration of individual tracks. A Dell computer containing the installed Pulse Time Data Recorder software was used for the observation and registration of measured vibrations. Applications implemented in Pulse LabShop and Matlab were used for the analysis of recorded data.

\section{Methodology of conducted research and assumed diagnostic criteria}

The measurements of mechanical vibrations conducted under conditions of normal operation of the tested transformer were carried out by means of measurement instruments described in Sec. 2. Points being the centre of the axis of symmetry of side walls of the tank were deemed to be the location of accelerometers (Fig. 3).

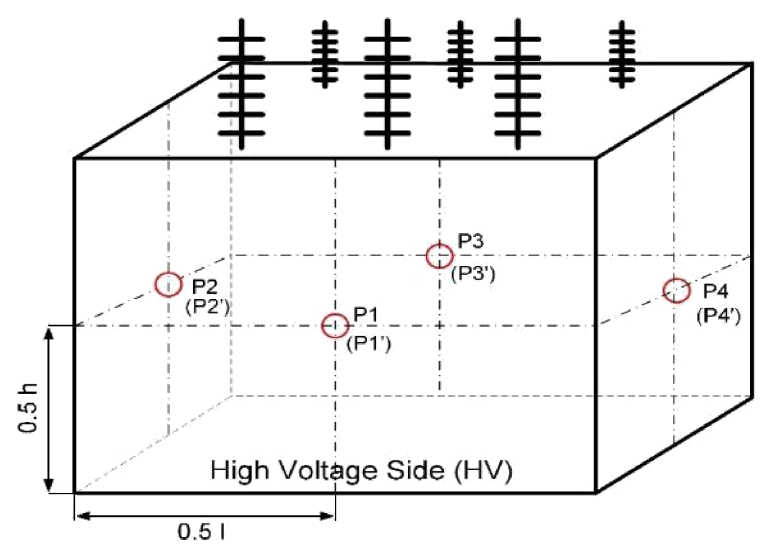

Fig. 3. Technical drawing of the transformer tank with marked vibration measurement points: $l$ - length, $h$ - height.

During the measurements, the location of converters on the tank was not changed in the case of any of the analysed states of the operation of the transformer (idle speed, load operation, commissioning). Points marked with symbols $\mathrm{P} 1-\mathrm{P} 4$ relate to the measurements and analysis of the results of vibrations recorded for the idle speed and commissioning of the transformer whereas points marked with symbols $\mathrm{P} 1^{\prime}-\mathrm{P} 4^{\prime}$ relate to the data obtained during the measurements carried out during the load operation of the transformer unit.

The evaluation of the measurement results obtained using the classical vibroacoustic method in the steady state operation of the transformer (idle speed, load operation) was based on the analysis of the following criterion values:

1) vibration components of up to $500 \mathrm{~Hz}$, as components deriving from and characterising magnetostrictive vibrations of the core,

2) vibration components within the range from 500 to $1500 \mathrm{~Hz}$, as components characterising the operation of cooling equipment,

3) vibration components within the band above $1500 \mathrm{~Hz}$, as components generated by and characterising the operation of the core of the analysed transformer (KAźMIERSKI et al., 2013).

In the evaluation of assumed criterion values the analysis mainly focused on two parameters, namely the amplitude spectrum within the range from $1500 \mathrm{~Hz}$ do $2500 \mathrm{~Hz}$ and the effective value of vibration acceleration within the range from $100 \mathrm{~Hz}$ to $2500 \mathrm{~Hz}$. Detailed diagnostics criteria of the classical vibroacoustic method on the basis of (KAźMIERSKI et al., 2013) are presented in Table 3. 
Table 3. Criterion values of the classical vibroacoustic method (KAŹMIERSKI et al., 2013).

\begin{tabular}{|c|c|c|}
\hline $\begin{array}{c}\text { Transformer } \\
\text { status }\end{array}$ & $\begin{array}{c}\text { Effective value } \\
\text { of vibration } \\
\text { acceleration } \\
\text { in the band } \\
100-2500 \mathrm{~Hz}\end{array}$ & $\begin{array}{c}\text { Effective value } \\
\text { of harmonic } \\
\text { vibration component } \\
\text { acceleration } \\
\text { in the band } \\
1500-2500 \mathrm{~Hz}\end{array}$ \\
\hline Normal & $\leq 400$ & $<10$ \\
\hline Warning & $400-1000$ & $10-30$ \\
\hline Alarm & $1000-2500$ & $>30$ \\
\hline Emergency & $>2500$ & $>30$ \\
\hline
\end{tabular}

The evaluation of the results obtained on the basis of research carried out using the method for the evaluation of the technical condition of the mechanical structure of transformer cores, so-called the modified vibroacoustic method, developed in the Institute of Electrical Power and Renewable Energy of the Opole University of Technology, was conducted on the basis of the analysis of changes in the specific harmonic vibration acceleration values versus time. As a result of the research conducted (BORUCKI, 2009; 2014; BoruCKI, CiCHOŃ, 2010), it was found that after passing from the transient state to the steady state of the operation of the transformer, the occurrence of the broad and continuous frequency band with constant amplitude of harmonic components in the range of the upper band of analysed accelerations corresponds to the transformer without damage. However, after passing from the transient state to the steady state of the operation of the transformer, the occurrence of the narrow frequency band with variable amplitude of harmonic components in the range of the upper band of analysed accelerations corresponds to the unit with suspected damage to the magnetic circuit.

\section{Analysis of the results of vibroacoustic measurements}

In order to determine the causes of the high concentration of gases dissolved in oil of the monitored transformer and confirm the diagnosis made on the basis of the results of the DGA, the measurements of vibrations using the classical and modified vibroacoustic method were carried out. Subsection 4.1 presents the results obtained in the trials carried out in the steady state of the operation of the transformer, while Subsec. 4.2 shows the test results obtained at the time of the idle speed of the transformer.

\subsection{Results of measurements carried out in the steady state of the operation of the transformer}

Figure 4 and Tables $4-5$ present the results of the analysis of vibroacoustic signals recorded during the no-load operation of the transformer (points P1-P4) and the load operation of the transformer constituting approx. $65 \%$ of the rated power of the transformer (points $\left.\mathrm{P} 1^{\prime}-\mathrm{P} 4^{\prime}\right)$.

a)

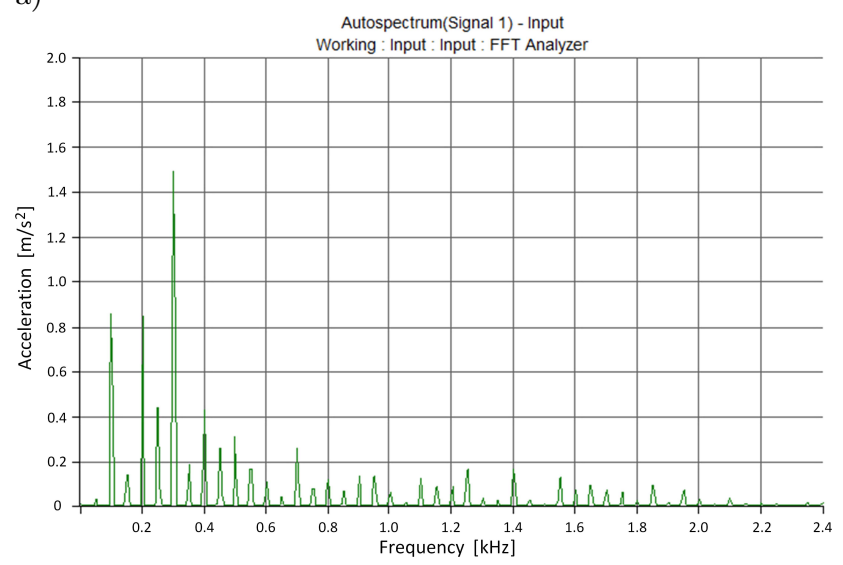

b)

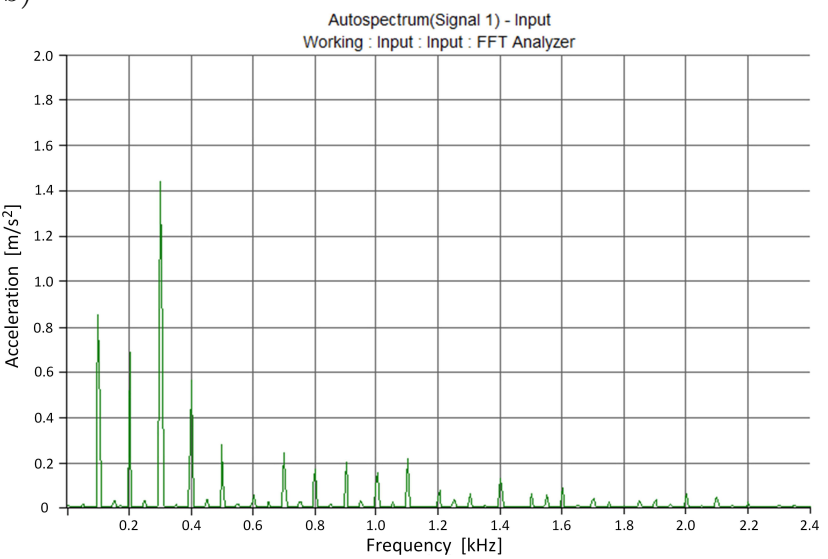

Fig. 4. Examples of amplitude spectra of recorded vibroacoustic signals: a) measuring point P1, idle speed, b) measuring point $\mathrm{P} 1^{\prime}$, load operation.

It was stated on the basis of the analysis of the amplitude spectrum of vibrations of the transformer determined at the idle speed and compared to the limit spectrum (Table 3 ) that the values of dominant spectral components within the band above $1500 \mathrm{~Hz}$ (Table 4) exceed the level of $10 \mathrm{~cm} / \mathrm{s}^{2}$ (warning status) in two measuring points: P2 and P4. However, none of the components exceeds the value considered to be the alarm value. Effective values of vibration acceleration within the band 100-2500 Hz (Table 5) exceed the limit value of $400 \mathrm{~cm} / \mathrm{s}^{2}$ in two measuring points (P3 and P4). The evaluation of the vibroacoustic indicators determined for the load operation of the device gave results relatively similar to those obtained for the idle speed. The values of the dominant spectral components within the band above $1500 \mathrm{~Hz}$ (Table 4) also exceed the level of $10 \mathrm{~cm} / \mathrm{s}^{2}$ in the same measuring points $\left(\mathrm{P} 2^{\prime}\right.$ and $\left.\mathrm{P} 4^{\prime}\right)$. None of the harmonics exceeds $30 \mathrm{~cm} / \mathrm{s}^{2}$ either. Similarly to the above, effective values 
Table 4. Frequency components of the acceleration of vibrations of the transformer tank determined within the band 1500-2500 Hz (idle speed, point P1-P4; load operation, points $\mathrm{P} 1^{\prime}-\mathrm{P} 4^{\prime}$ ).

\begin{tabular}{|c|c|c|c|c|c|c|c|c|}
\hline \multirow{3}{*}{ Dominant spectral components } & \multicolumn{8}{|c|}{ Effective value of vibration acceleration $\left[\mathrm{cm} / \mathrm{s}^{2}\right]$} \\
\hline & \multicolumn{8}{|c|}{ Measuring point no. } \\
\hline & $\mathrm{P} 1$ & P1 & $\mathrm{P} 2$ & $\mathrm{P} 2 \prime$ & P3 & P3/ & $\mathrm{P} 4$ & $\mathrm{P} 4 \prime$ \\
\hline 1500 & 0.3 & 5.3 & 8.0 & 15.7 & 8.5 & 8.5 & 11.8 & 10.0 \\
\hline 1600 & 9.8 & 7.8 & 17.7 & 25.1 & 2.7 & 6.7 & 3.1 & 3.9 \\
\hline 1700 & 6.8 & 2.4 & 3.1 & 1.9 & 1.2 & 5.5 & 5.8 & 4.8 \\
\hline 1800 & 2.3 & 0.7 & 2.8 & 2.9 & 1.7 & 4.5 & 4.9 & 3.1 \\
\hline 1900 & 1.6 & 3.3 & 1.5 & 2.5 & 1.6 & 2.5 & 11.6 & 12.5 \\
\hline 2000 & 2.6 & 5.4 & 4.9 & 4.2 & 1.4 & 3.6 & 12.1 & 9.5 \\
\hline 2100 & 2.7 & 4.3 & 2.4 & 1.0 & 1.2 & 1.4 & 3.9 & 6.3 \\
\hline 2200 & 2.1 & 2.2 & 4.7 & 3.3 & 2.2 & 1.3 & 3.8 & 4.9 \\
\hline 2300 & 1.1 & 1.1 & 1.2 & 0.8 & 0.5 & 1.8 & 6.3 & 6.8 \\
\hline 2400 & 1.3 & 0.4 & 1.8 & 1.4 & 0.6 & 3.3 & 1.4 & 4.8 \\
\hline 2500 & 1.0 & 1.3 & 1.8 & 1.0 & 0.4 & 0.2 & 1.8 & 2.3 \\
\hline
\end{tabular}

Table 5. Effective values of acceleration of vibrations of the transformer tank determined within the band $100-2500 \mathrm{~Hz}$ (idle speed, points $\mathrm{P} 1-\mathrm{P} 4$; load operation, points $\mathrm{P} 1^{\prime}-\mathrm{P} 4^{\prime}$ ).

\begin{tabular}{|c|c|c|c|}
\hline \multicolumn{4}{|c|}{$A_{r m s}\left[\mathrm{~cm} / \mathrm{s}^{2}\right]$} \\
\hline \multicolumn{3}{|c|}{ Idle speed } & \multicolumn{2}{c|}{ Load operation } \\
\hline $\mathrm{P} 1$ & 213.0 & $\mathrm{P} 1^{\prime}$ & 202.3 \\
\hline $\mathrm{P} 2$ & 342.2 & $\mathrm{P}^{\prime}$ & 394.2 \\
\hline $\mathrm{P} 3$ & $\mathbf{5 5 6 . 5}$ & $\mathrm{P} 3^{\prime}$ & $\mathbf{4 7 7 . 6}$ \\
\hline $\mathrm{P} 4$ & $\mathbf{7 1 7 . 3}$ & $\mathrm{P} 4^{\prime}$ & $\mathbf{7 6 6 . 8}$ \\
\hline
\end{tabular}

of vibration acceleration within the band $100-2500 \mathrm{~Hz}$ (Table 5) exceed the warning status in two measuring points: $\mathrm{P} 3^{\prime}$ and $\mathrm{P} 4^{\prime}$.

The comparative analysis of vibroacoustic signals recorded during the steady state of the operation of the transformer (idle speed and load operation) gave similar values of indicated vibroacoustic indicators. Therefore, the conducted analysis shows that the magnetic circuit of the transformer is responsible for the generation of the increased level of mechanical vibrations of the tested transformer, and the participation of vibrations of windings caused by current flowing through them is relatively insignificant. Increased vibration indicators determined using the classical vibroacoustic method may indicate a gradual loss of rigidity of the mechanical structure of the core of the diagnosed transformer unit.

\subsection{Results of vibroacoustic measurements carried out in the transient state of the operation of the transformer}

Figures 5-7 present exemplary results of the STFT, CWT and DWT analysis of vibroacoustic signals measured at the idle speed of the transformer. Figures marked with letter (a) relate to the analysis of a)

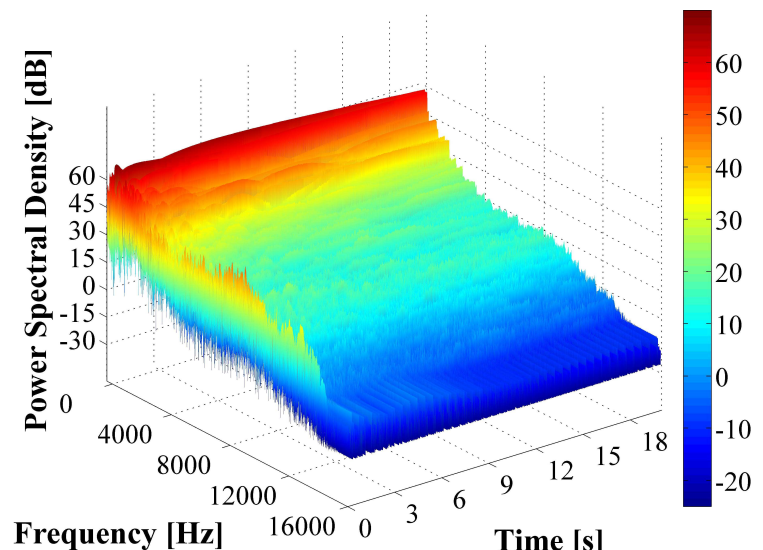

b)

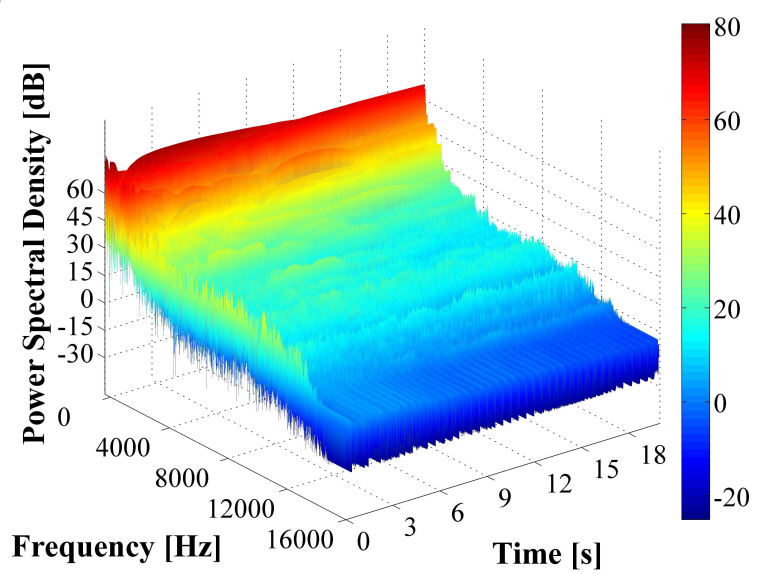

Fig. 5. Three-dimensional spectrograms of power spectral density of vibration acceleration of the attached transformer at the idle speed: a) measuring point P1, b) measuring point $\mathrm{P} 3$.

vibrations recorded in the measuring point $\mathrm{P} 1$, while those marked with letter (b) relate to the measuring point P3. 
a)
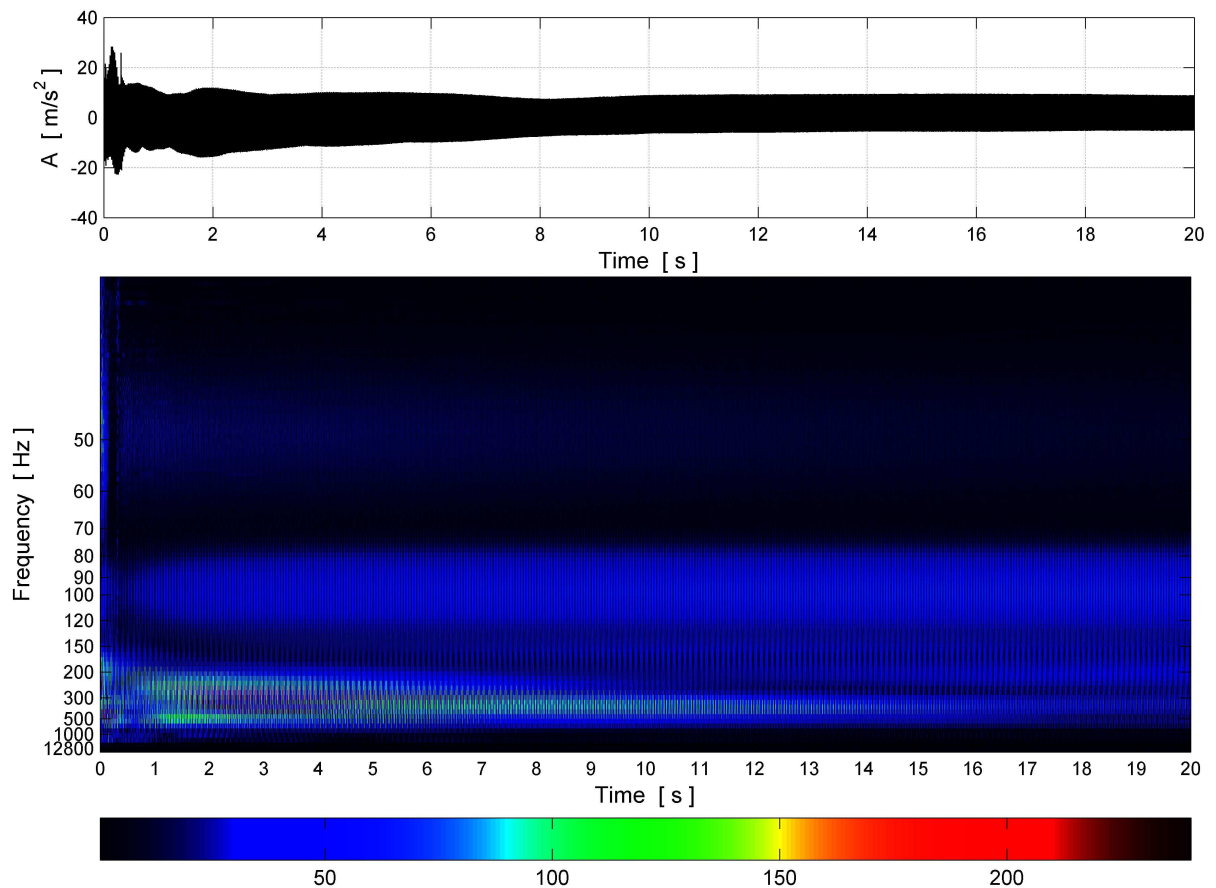

b)
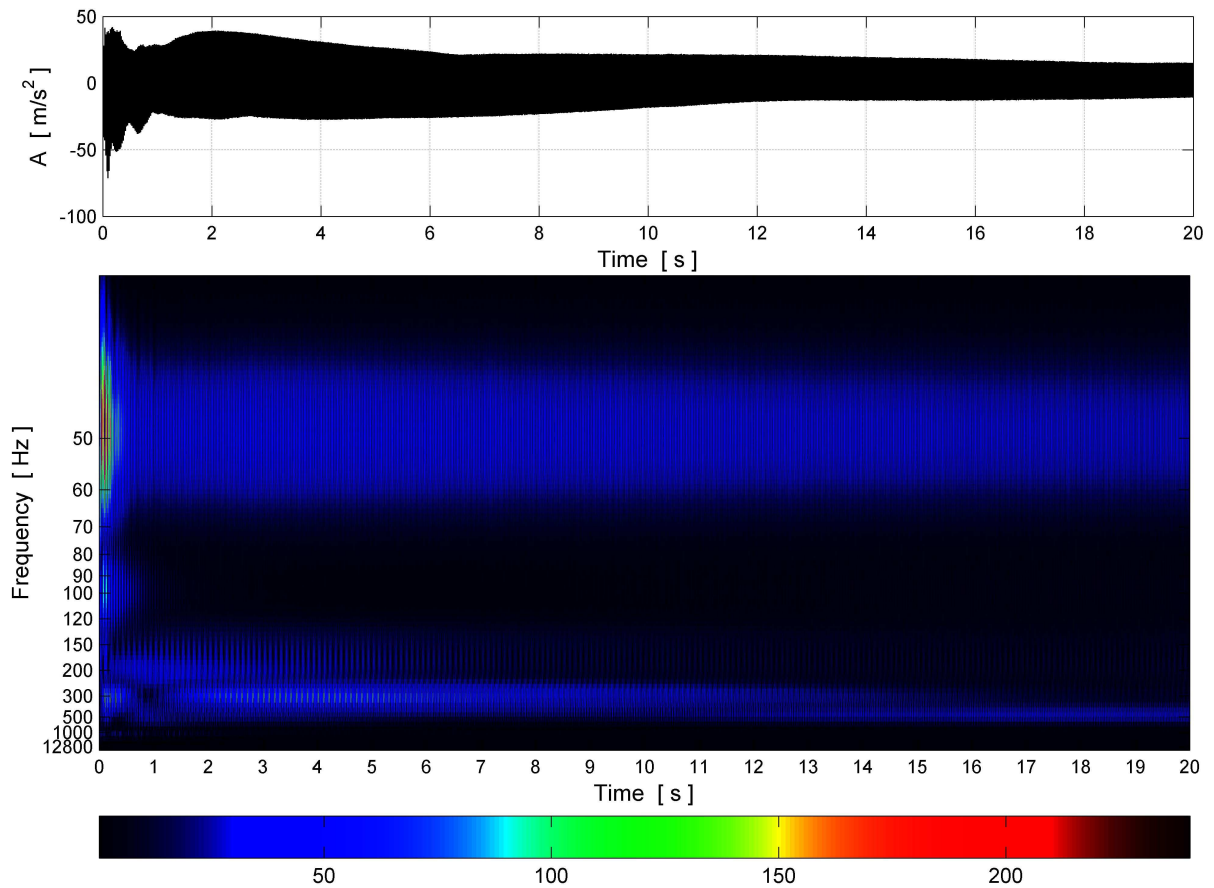

Fig. 6. Scalograms of vibration acceleration of the attached transformer at the idle speed: a) measuring point $\mathrm{P} 1$, b) measuring point $\mathrm{P} 3$.

Three-dimensional spectrograms of power spectral density of vibration acceleration presented in Fig. 5 are characterised by the narrow frequency band for times $t>0.5 \mathrm{~s}$. The presence of the narrowband frequency structure in the vibroacoustic signal measured at the time of switching on the device and during the first several seconds of the transient state of its operation as well as a significant increase in the values of components in the band up to $1000 \mathrm{~Hz}$, for $t>10 \mathrm{~s}$, prove that the core is defective. STFT spectrograms obtained in this case are characterised by a clear similarity to spaces indicated during laboratory experiments on objects with modelled damage (BORUCKI, 2012a). Continuous wavelet transform (CWT) scalograms presented in Fig. 6 are characterised by the presence of broadband coherent structures only in range up to approx. $1000 \mathrm{~Hz}$. In addition, main wavelet structures covering the range of low frequencies are visible in CWT scalograms at the time of switching on the diagnosed unit. 
a)

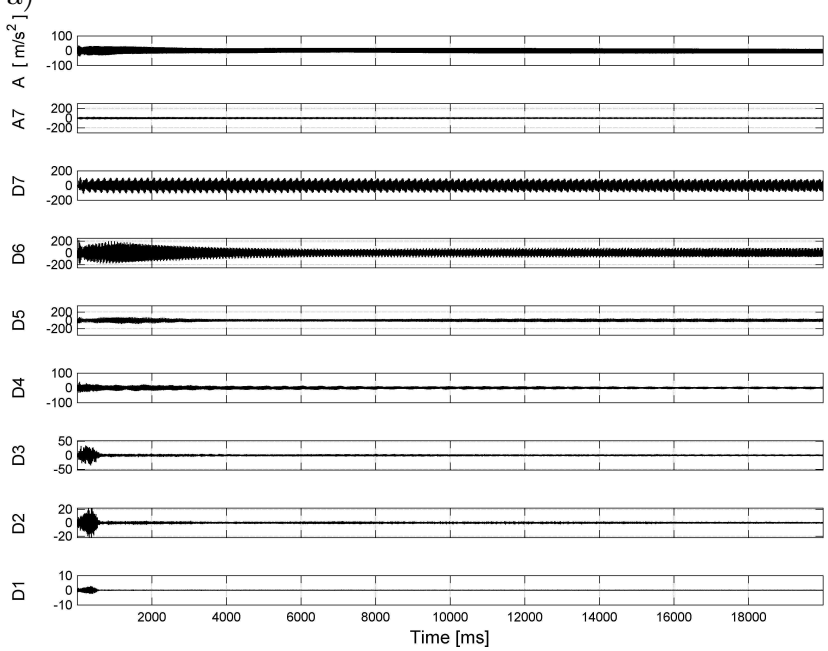

b)

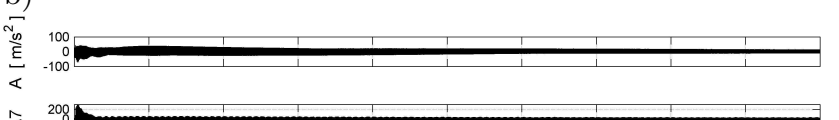

$\&$

ลิ

๑

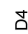

ธ

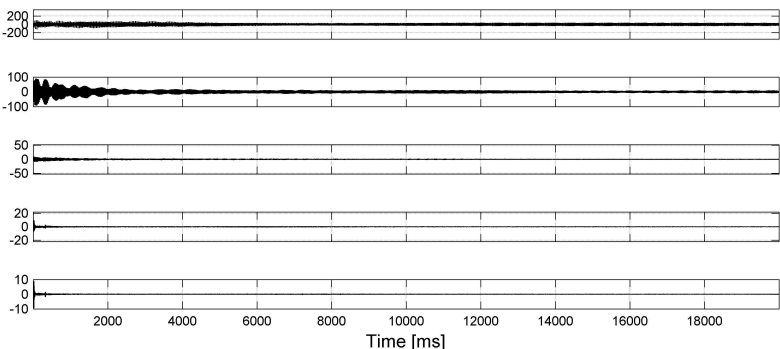

Fig. 7. Waveforms of DWT of vibration acceleration of the attached transformer at the idle speed: a) measuring point $\mathrm{P} 1, \mathrm{~b})$ measuring point P3.

The lack of high-frequency structures in recorded vibroacoustic signals is also confirmed by the results of the discrete wavelet transform (DWT) illustrated in Fig. 7. The figures below present a clear change in the amplitude of waveforms in the range of frequencies corresponding to details D4-D7 (band 1024-2048, $512-1024,256-512,128-256 \mathrm{~Hz}$ ) and a visible decrease in the participation of power structures represented by high-frequency details D1-D3 (band 8192-16384, 4096-8192 and 2048-4096 Hz).

\section{Conclusion}

The results of the analysis of vibrations of the transformer of type TFR 250000/400 carried out under conditions of normal operation, presented in this article confirmed the possibility of using diagnostic methods prepared and developed at the Opole University of Technology in the industry. Thanks to the compar- ison of the results of the DGA of insulating oil with the results obtained using the classical and modified vibroacoustic method, it was possible to confirm the loss of the rigidity of the mechanical structure of the active part of the tested transformer - loosening and loss of rigidity of the mechanical structure of its core. Research conducted on the high power unit confirmed that the use of the classical and modified vibroacoustic method in the diagnostics of transformers allows for the non-invasive evaluation of the technical condition of their cores. According to the authors, the vibroacoustic methods should be currently used in the diagnostics of transformers as an important addition to existing measurement methods, in particular the DGA of oil on the basis of which a preliminary evaluation of the technical condition of the active part of these devices is carried out.

Due to the limited frequency band of the vibroacoustic signal recorded at the time of the commissioning of the tested transformer (Figs. 5-7), as well as the increased values of vibration indicators determined for the steady state operation (Tables 4-5), and the high concentration of flammable gases in oil (Table 2), constant monitoring of their increase using the DGA method was recommended. In case of the acceleration of dynamics of the increase in the concentration of specific typical gases, it was also recommended to carry out vibroacoustic measurements once again and, in case of their negative results, to carry out an internal inspection of the diagnosed transformer.

\section{References}

1. Bartoletti C., Dedideerio M., et al. (2004), VibroAcoustic Technique to Diagnose Power Transformers, IEEE Trans. on Power Del., 19, 1, 221-229.

2. BorUCKI S. (2009), Vibroacoustic Measurements in a Transient State of Transformer Operatrion, Acta Physica Polonica A, 116, 277-280.

3. Borucki S. (2012a), Diagnosis of Technical Condition of Power Transformers Based on the Analysis of Vibroacoustic Signals Measured in Transient Operating Conditions, IEEE Trans. on Power Del., 27, 670-676.

4. Borucki S. (2012b), Method for assessing technical condition of transformer, involves analyzing vibration acceleration, and locating small and narrow bands at harmonic components of upper band after passing transient to steady-state operation of transformer, Patent Number PL394036-A1; PL219843-B1, Politechnika Opolska.

5. BORUCKI S. (2014), Used of modified vibroacoustic method for diagnostics of power transformer cores, Studia i Monografie, No. 384, Printing House of Opole University of Technology, Opole.

6. Borucki S., Cichoń A. (2010), The influence of power transformer load on vibroacoustic signal analysis results, Przegląd Elektrotechniczny, 86, 45-47. 
7. Dwojak J., Rzepiela M. (1999), Vibration diagnostics status of machinery and equipment, Practical quide [in Polish], Printing House of Biuro Gamma, Warszawa.

8. Kaźmierski M., Olech W. (2013), Technical diagnostics and monitoring of transformers [in Polish], Printing House of ZPBE Energopomiar-elektryka Sp. z o.o., Gliwice.

9. Léonard F., Foata M., Paquin J.Y. (2000), VibroAcoustic Signature Comparison and Time-Warping Correction with Multi-Scale Correlation, Mech. Sys. and Sig. Proc., 14, 3, 443-458.

10. Mizokami M., Yaвumoto M., Okazaki Y. (1997), Vibration Analysis of a 3-Phase Model Transformer Core, El. Eng. in Japan, 119, 1, 1-8.
11. Shengchang J., Youngfen L., Yanming L. (2006), Research on Extraction Technique of Transformer Core Fundamental Frequency Vibration Based on OLCM, IEEE Trans. on Power Del., 21, 4, 1981-1988.

12. Szymaniec S. (2006), Diagnosis of the state of the winding insulation and bearing condition squirrel cage induction motors in terms of industrial exploitation [in Polish: Diagnostyka stanu izolacji uzwojen $i$ stanu tożysk silników indukcyjnych klatkowych $w$ warunkach przemysłowej eksploatacji], Studia i Monografie, No. 193, Printing House of Opole University of Technology, Opole.

13. Wotzka D., Boczar T., Malec T., Pierzga R. (2013), Analysis of Vibro-Acoustic Signals Generated during Operation of Micro Wind Turbines, Acta Physica Polonica A, 124, 595-597. 